\title{
Anterior cervical corpectomy and fusion with stand-alone cages in patients with multilevel degenerative cervical spine disease is safe
}

\author{
Mohamed H. Tohamy ${ }^{1,2,3+} \oplus$, Georg Osterhoff ${ }^{4+}$, Ahmed Shawky Abdelgawaad ${ }^{2,5}$, Ali Ezzati $^{2}$ and \\ Christoph-E. Heyde 4,6* $^{\text {* }}$
}

\begin{abstract}
Background: In case of spinal cord compression behind the vertebral body, anterior cervical corpectomy and fusion (ACCF) proves to be a more feasible approach than cervical discectomy. The next step was the placement of an expandable titanium interbody in order to restore the vertebral height. The need for additional anterior plating with ACCF has been debatable and such technique has been evaluated by very few studies. The objective of the study is to evaluate radiographic and clinical outcomes in patients with multilevel degenerative cervical spine disease treated by stand-alone cages for anterior cervical corpectomy and fusion (ACCF).

Methods: Thirty-one patients (66.5 \pm 9.75 years, range 53-85 years) were analyzed. Visual Analog Scale (VAS) and the 10-item Neck Disability Index (NDI) were assessed preoperatively and during follow-up on a regular basis after surgery and after one year at least. Assessment of radiographic fusion, subsidence, and lordosis measurement of Global cervical lordosis (GCL); fusion site lordosis (FSL); the anterior interbody space height (ant. DSH); the posterior interbody space height (post. DSH); the distance of the cage to the posterior wall of the vertebral body (CD) were done retrospectively. Mean clinical and radiographic follow-up was $20.0 \pm 4.39$ months.

Results: VAS-neck $(p=0.001)$ and VAS-arm $(p<0.001)$ improved from preoperatively to postoperatively. The NDI improved at the final follow-up $(p<0.001)$. Neither significant subsidence of the cages nor significant loss of lordotic correction were seen. All patients showed a radiographic union of the surgically addressed segments at the last follow up.

Conclusions: Application of a stand-alone expandable cage in the cervical spine after one or two-level ACCF without additional posterior fixation or anterior plating is a safe procedure that results in fusion. Neither significant subsidence of the cages nor significant loss of lordotic correction were seen.
\end{abstract}

\footnotetext{
*Correspondence: Christoph-Eckhard.Heyde@medizin.uni-leipzig.de; Christoph.heyde2000@gmail.com

${ }^{\dagger}$ Mohamed H. Tohamy and Georg Osterhoff contributed equally to this work.

${ }^{6}$ Department of Orthopedics, Trauma and Plastic Surgery, University Hospital Leipzig, 04103 Leipzig, Germany

Full list of author information is available at the end of the article
}

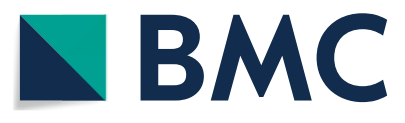

(c) The Author(s) 2021. Open Access This article is licensed under a Creative Commons Attribution 4.0 International License, which permits use, sharing, adaptation, distribution and reproduction in any medium or format, as long as you give appropriate credit to the original author(s) and the source, provide a link to the Creative Commons licence, and indicate if changes were made. The images or other third party material in this article are included in the article's Creative Commons licence, unless indicated otherwise in a credit line to the material. If material is not included in the article's Creative Commons licence and your intended use is not permitted by statutory regulation or exceeds the permitted use, you will need to obtain permission directly from the copyright holder. To view a copy of this licence, visit http://creativecommons.org/licenses/by/4.0/. The Creative Commons Public Domain Dedication waiver (http://creativeco mmons.org/publicdomain/zero/1.0/) applies to the data made available in this article, unless otherwise stated in a credit line to the data. 
Trial registration: Retrospectively registered. According to the Decision of the ethics committee, Jena on 25th of July 2018, that this study doesn't need any registration. https://www.laek-thueringen.de/aerzte/ethikkommission/ registrierung/.

Keywords: Cervical spine, Stand-alone cage, Corpectomy, Spinal canal stenosis, Anterior plate, Anterior cervical decompression, Cervical fusion, Dysphagia

\section{Background}

Cervical spine fusion is an international set process for handling degenerative cervical spine problem $[1,2]$.

Anterior cervical discectomy and fusion (ACDF) is used in treating symptomatic cervical spondylosis, degenerative disc disease and spinal canal stenosis (SCS), which results in a compression of one or more nerve roots and/or the spinal cord. The suitability and effectiveness of the technique have been proved in achieving functional recovery and easing the spinal and nerve pain. In addition, ACDF maintains the spinal column stability and promotes the sagittal balance [3-5]. In the case of foraminal stenosis, an anterior approach has the advantage that the disc as major contributor to nerve compression can be removed. In addition, the foramina can be addressed directly without weakening the posterior tension band.

For multilevel stenosis, however, decompression of the spinal canal may be insufficient through the disc space alone. Laminectomy and laminoplasty have proven their efficiency in these cases [6], but complications as C5 nerve root palsy, [7], axial neck pain, segmental instability and progressive cervical kyphosis are not infrequent $[8,9]$.

Alternatively, the application of expandable cages after Anterior Cervical Corpectomy and Fusion (ACCF), can prevent the damages in the posterior approach. ACCF from $\mathrm{C} 3-\mathrm{C} 7$ is being used to decompress and reconstruct the cervical spine for a wide variety of degenerative disorders, trauma, neoplasms and infectious disorders.

In degenerative diseases, the indication for corpectomy is the compression that extends beyond the disc space and behind the vertebral body (VB). In such cases, performing corpectomy is essential to achieve adequate spinal cord decompression. Followed by reconstruction, ACCF permits the most direct and proper decompression of the anterior spinal cord or resection of lesions that involve the cervical VBs and improve the cervical lordosis [10]. The technique minimally disrupts healthy cervical muscles and is associated with a low risk of injuring surrounding structures [11, 12]. It has been shown that an only-anterior approach for multiple levels can lead to good results in patients with ossification of the posterior longitudinal ligament (OPLL) and patients with a spinal canal occupancy ratio of $\geq 50 \%$ managed by anterior surgery alone had better results [13]. Even though dysphagia and dyspnea are potential complications, the anterior approach is associated with little morbidity and usually results in earlier postoperative recovery compared to open posterior procedures [14, 15]. Some surgeons, however, favour a combined anterior and posterior approach for multilevel fusion as anterioralone constructs may be susceptible to failure and loss of correction because of mechanical disadvantages [16, 17]. Others suggested to add anterior plating in ACCF constructs in order to maintain sufficient stability until osseous fusion is achieved.

Hence, the aim of this study is to evaluate radiographic and functional outcome in a series of patients with multilevel degenerative cervical spine disease treated by standalone cages for ACCF.

\section{Methods}

\section{Patients}

All patients who had undergone one-or two level ACCF for SCS with or without cervical spondylosis affecting the levels C3/4 to C7/T1 in a tertiary spine center between 2014 and 2016 were identified in a retrospective chart review.

Further inclusion criteria were neck or radicular upper extremity pain and/or neurological deficit due to compression of nerve roots or the spinal cord confirmed by computed tomography $(\mathrm{CT})$ and/or magnetic resonance imaging (MRI). Patients with previous surgery at the index level, systemic or local infection, rheumatoid arthritis (RA), non-controlled diabetes mellitus (DM), patients with a known allergy to any of the materials contained in the cage implant and patient with progressive malignancy within the last five years were excluded. None of the patients received osteo-anabolic therapy like teriparatide or denosumab.

In total, 31 patients (mean age $66.5 \pm 9.75$ years, range $53.0-85.00$ years, 10 female) were included in this study (Table 1). One patient had OPLL, and six patients presented with neurological impairment without history of trauma which illustrated in (Suppl1).

\section{Surgical technique}

In all patients, ACCF was performed through a standard anterior cervical approach by microscopy-assisted dissection [18]. After a corpectomy and decompression, a 
Table 1 Patients' baseline characteristics

\begin{tabular}{lll}
\hline & $\begin{array}{l}\text { Number } \\
\boldsymbol{n} \boldsymbol{n = 3 \mathbf { 1 } ^ { \prime }}\end{array}$ & Percent \\
\hline Age & & \\
$<60$ & 10 & 32.3 \\
$60-70$ & 8 & 25.8 \\
$70+$ & 13 & 41.9 \\
Range & $53.0-85.00$ & \\
Mean \pm S.D & $66.5 \pm 9.75$ & \\
Sex & & \\
Male & 21 & 67.7 \\
Female & 10 & 32.3 \\
Level & & \\
3 & 2 & 6.45 \\
4 & 4 & 12.90 \\
5 & 4 & 12.90 \\
6 & 7 & 22.58 \\
7 & 1 & 3.23 \\
$4+5$ & 6 & 19.35 \\
$5+6$ & 7 & 22.58 \\
\hline
\end{tabular}

cervical expandable titanium cage (X-Core ${ }^{\circledR}$ Mini, NuVasive, San Diego, USA) was introduced into the multilevel void. The cage was then expanded under fluoroscopic control until sufficient correction of the cervical spinal alignment could be achieved.

\section{Clinical evaluation}

Clinical examinations were performed before surgery and at final follow-up. As a standard, this included documentation of neck and arm pain by the visual analog scale (VAS) [19] and assessment of functional outcome by the 10-item NDI (German version) [20]. Patient selfreported dysphagia-related symptoms were graded as "none," "mild," "moderate" and "severe" as previously described by Bazaz et al. [18]. Additionally, the amount of dysphagia-associated pain (VAS 0-10) and the duration of dysphagia-related symptoms were recorded.

\section{Radiologic assessment}

Plain radiographs with an anteroposterior view and lateral views in flexion and extension were taken preoperatively, postoperatively and at final follow-up and were evaluated by three experienced spine surgeons.

Evaluation of global cervical lordosis (GCL) and fusion site lordosis (FSL):

Changes of the lordotic cervical alignment were measured using a modification of the method described by Faldini et al. of the cervical interbody fusion [21].
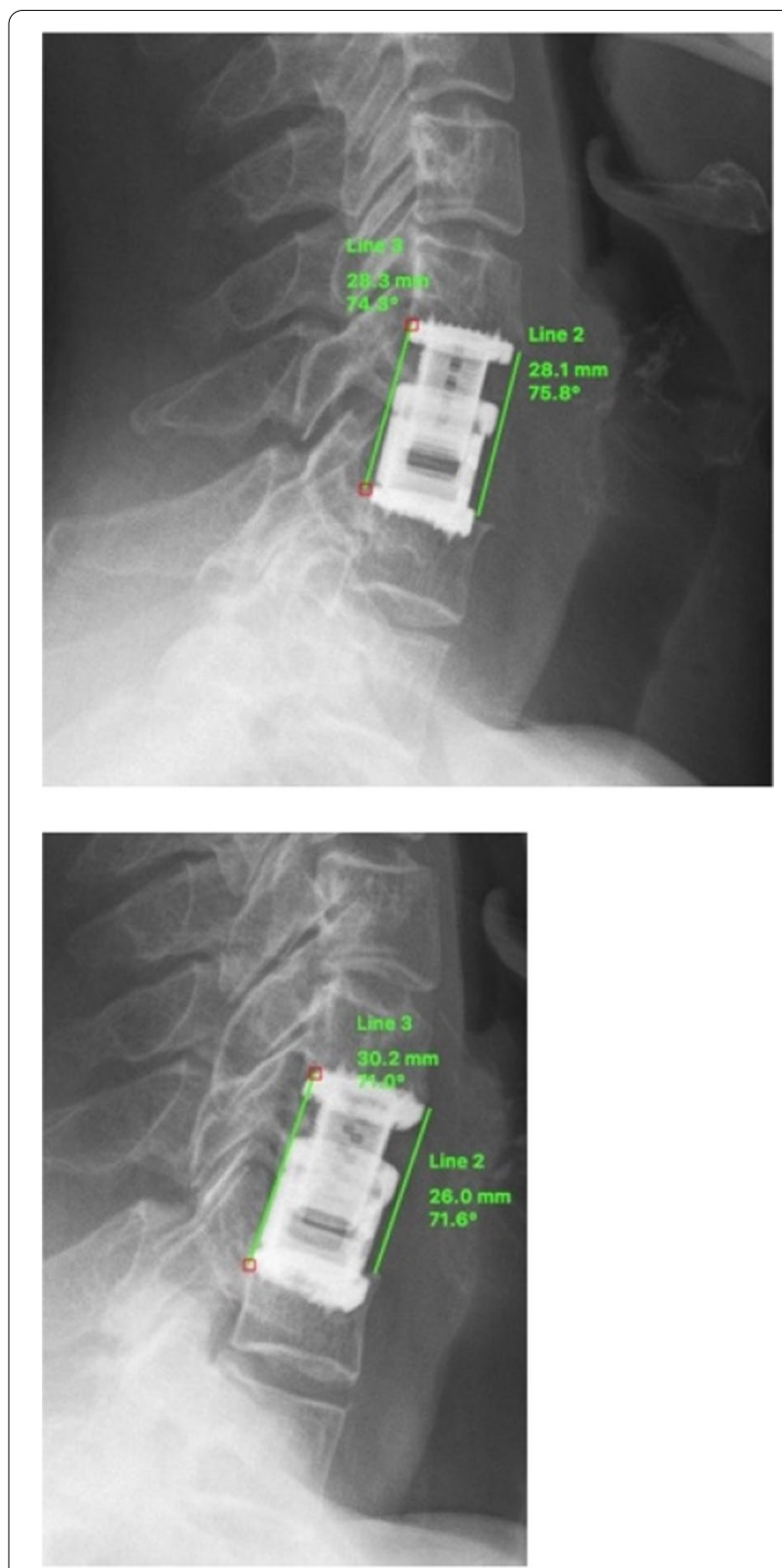

Fig. 1 Measurement of Fusion Site Lordosis (FSL) postoperatively (left), then I would like to put the pic. on the left side or we have to write (up) and at last follow-up (right), then I would like to put it on the right side or we have to write down instead of right

GCL was measured between the upper endplate of C3 and the lower border of C7. FSL was measured between the upper endplate of the cranial fusion site vertebra and the lower endplate of the caudal fusion site vertebra (bi-segmental FSL, Fig. 1). For cervical alignment, positive values represent lordosis while negative values indicate kyphotic alignment. 


\section{Evaluation of cage migration and subsidence}

The same method as described by Gercek et al. was used [22]. Cage migration and subsidence were assessed by measuring the distance between the posterior edge of the implant and the posterior wall of the lower endplate as well as the anterior and posterior interbody space height on lateral plain radiographs postoperatively and at the end of the follow-up. Migration or settling were defined as changes of $3 \mathrm{~mm}$ or more of the following parameters: the anterior interbody space height (ant. DSH), the posterior interbody space height (post. DSH) and the distance of the cage to the posterior wall of the vertebral body (CD) [22] (Fig. 2).

\section{Evaluation of the fusion}

Fusion was evaluated as decribed by (Choudhri, T. F., Mummaneni) [23], (Lee CS, Chung SS, Choi SW, et al.) [24] and (Cannada LK, Scherping SC, Yoo JU, et al.) [25].

The first criterion indicating nonunion was change in endplate angles in flexion and extension in the lateral

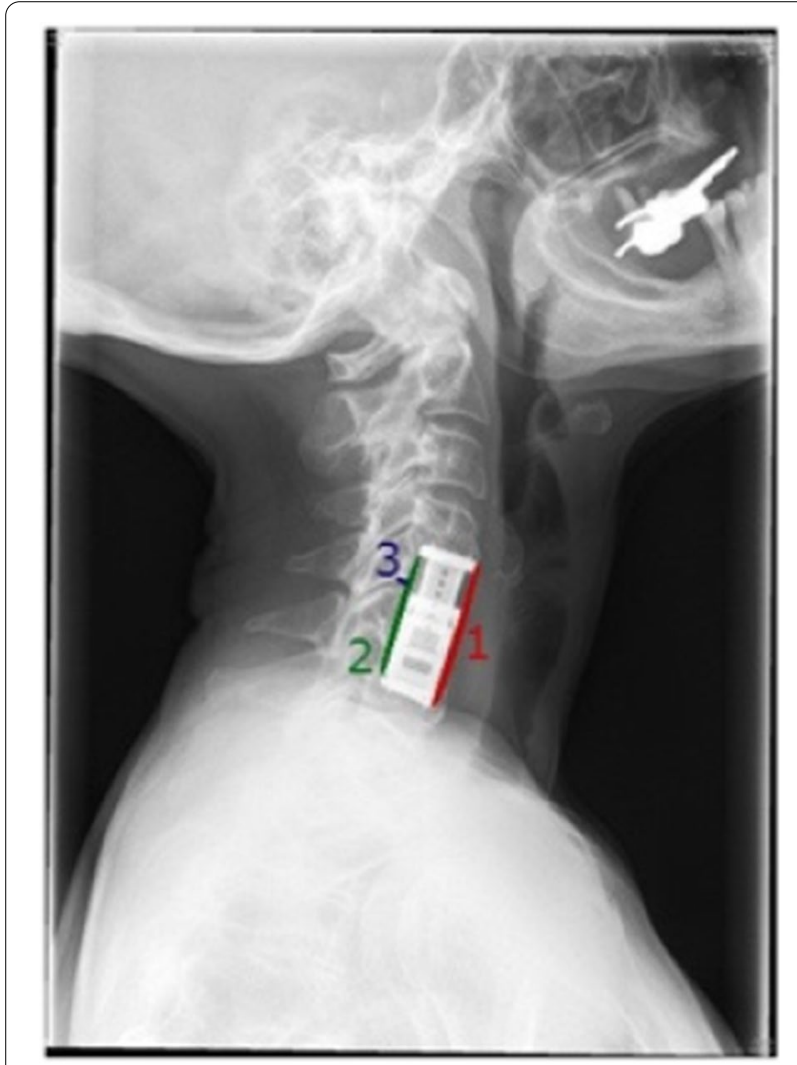

Fig. 2 Measurement of cage migration and subsidence1: anterior DSH, 2: posterior DSH, 3: CD. Modified Gercek et al. view of more than 2 degrees (Fig. 3). The second criterion for nonunion was a change of more than $2 \mathrm{~mm}$ in the distance between the tips of the spinous processes of the surgically managed levels on flexion and extension lateral views (Fig. 4 and Fig. 5) [25]. In case one of these two criteria was noticed, the segment was considered not fused.

If continuous trabecular bone bridges could be confirmed at 12 months FU (at any one of the following locations: anterior, posterior, lateral or within the cage), the segment was classified as fused. In case of absence of any bony bridge or confirmation of a complete bony discontinuity within the disc space, the segment was classified as not fused [26] as illustrated in (Fig. 6).

In case of potential nonunion in the radiographic evaluation, CT (sagittal and coronal two-dimensional) was used.

The height as well as the angle of the fused segment $\mathrm{C} 2-\mathrm{C} 7$ were measured and analyzed preoperatively immediately after surgery and at the final follow-up.

Mean clinical and radiographic follow-up was $20.0 \pm 4.39$ months (range 12 to 27 months).

\section{Statistical analysis}

Statistical analysis was done using Statistical Package for Social Sciences (SPSS/version 20, SPSS Inc., Chicago, IL, USA) [27].

Unless otherwise denoted, data was summarized as mean \pm standard deviation.

Student's t-test was used to compare differences in means between two groups and an.

ANOVA test was used for parametric data to distinguish between three groups. Spearman-Rho coefficients were calculated to assess potential bivariate associations. The level of significance was defined as $p<0.05$.

\section{Results \\ Clinical outcome}

The preoperative VAS-neck increased postoperatively $(p=0.013)$ and then improved at final followup $(p=0.001)$. The preoperative VAS-arm decreased $(p=0.001)$ at the end of follow up, the VAS-arm was not statistically different to the postoperative $(p=0.336)$.

The value for the NDI improved from an initial presentation $(p=0.001)$ and at final follow-up $(p=0.001)$. No revision surgeries were necessary.

As for dysphagia-related symptoms, 20 patients out of 31 patients $(64.5 \%)$ had mild symptoms like difficulty in swallowing. In all cases, these symptoms disappeared within two days after surgery. No patient had dysphagia at the time of discharge. 


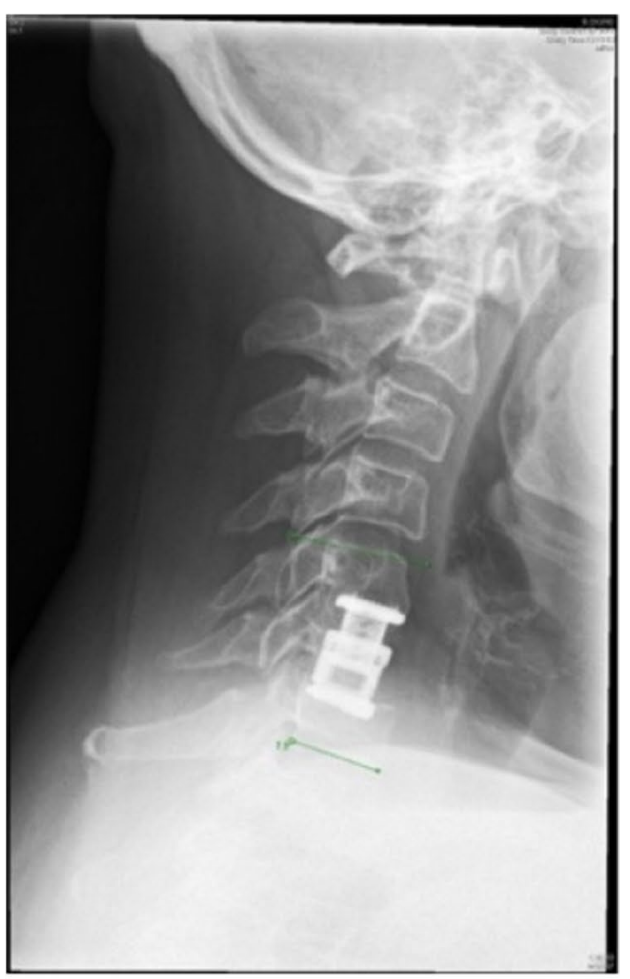

Fig. 3 Evaluation of fusion: Changes in flexion and extension of the lateral view of the cervical spine of more than $2 \mathrm{~mm}$ indicate nonunion

\section{Radiographic outcome}

Evaluation of global cervical lordosis (GCL) and fusion site lordosis (FSL):

Compared to the preoperative measurement $\left(11.8^{\circ} \pm 8.19^{\circ}\right), \mathrm{GCL}$ was significantly increased postoperatively $\left(15.8^{\circ} \pm 7.34^{\circ}, p=0.025\right)$ and at final follow up $\left.14.9^{\circ} \pm 7.12^{\circ}, p=0.021\right)$ while these postoperative measurements showed an insignificant difference $(p=0.319)$. In contrast, postoperative $\left(7.5^{\circ} \pm 3.90^{\circ}\right)$ and follow-up FSL measurements $\left(7.9^{\circ} \pm 5.41^{\circ}\right)$ showed no significant differences compared to the preoperative values $\left(7.1^{\circ} \pm 4.35^{\circ}, p=0.261 / 0.379\right)$.

\section{Cage migration and subsidence}

The comparison between anterior DSH, posterior DSH and the CD postoperatively and at last follow-up showed no change in anterior and posterior DSH, but a significant decrease in $\mathrm{CD}$ showed between postoperative and follow-up measurement $p=0.05$ (Table 2).

No significant correlation was found between GCL

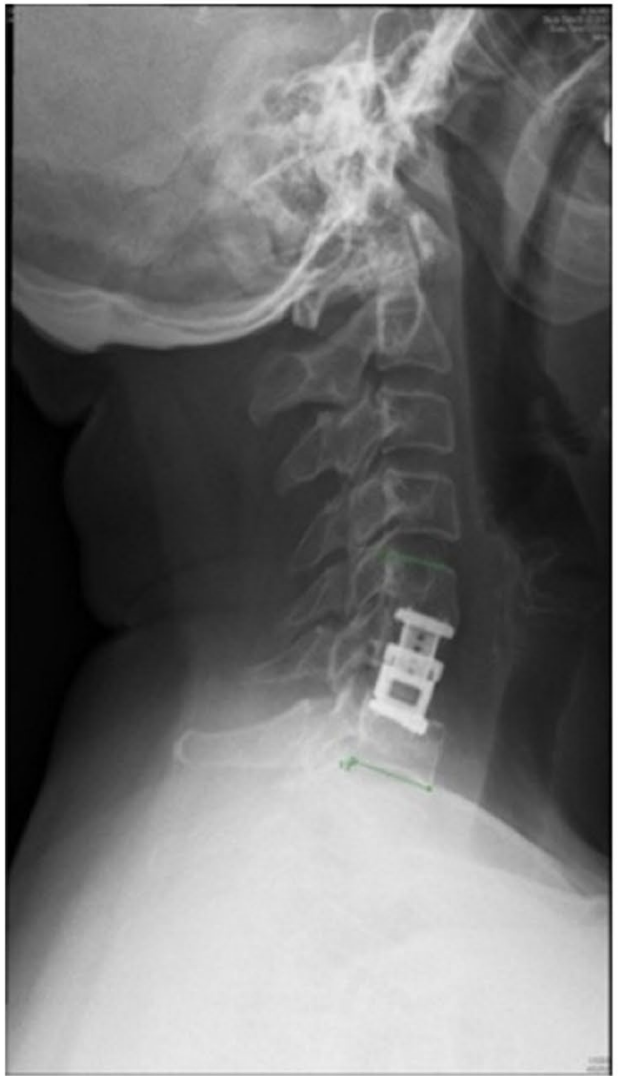
and both anterior and posterior DSH $(p=0.463 / 0.401)$. There was also no significant relationship between radiographic and clinical outcome parameter (Table 3).

From postoperative to last follow-up, a subsidence of the anterior and posterior DSH and CD were observed of $5.68,6.38$, and $14.71 \%$, respectively.

\section{Evaluation of the fusion}

All the thirty-one patients had radiographic fusion at the last follow-up examination demonstrated by bridging bone between the vertebral bodies or by the absence of motion on dynamic radiographs (Figs. 3 and Fig. 6). After one year postoperatively, one patient suffered from a remarkable neck pain, but nonunion was excluded by CT (Fig. 6).

\section{Discussion}

This study aimed to evaluate radiographic and functional outcome in patients with multilevel degenerative cervical spine disease treated by stand-alone cages for ACCF.

In this series, neither significant subsidence of the cages nor significant loss of lordotic correction were seen. Some patients had dysphagia-related symptoms, but these resided within two days in all patients. Pain and functional outcome improved with surgery and this improvement was maintained during follow-up. Those patients who survived until radiographic follow-up. 31 

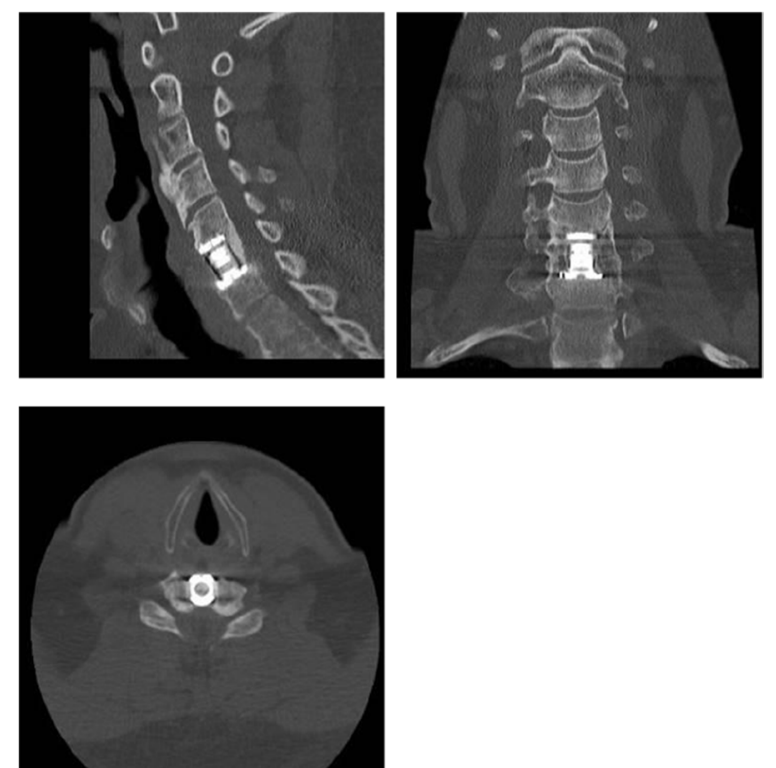

Fig. 4 A CT scan at final follow-up shows fusion with presence of bone mass inside the cage

patients showed a good bony fusion of the surgically addressed segments without any surgical revision or site infection.

Regarding which surgical approach is more effective for the treatment of multilevel CSM, no definitive conclusion could be reached in a systematic review and meta-analysis of Leuo et al. [28]. The anterior approach was associated with better postoperative neurological results compared to the posterior approach. However, there was no apparent difference in the long-term neurological recovery rate.

Patients with multilevel CSM, who underwent ACCF, used to be treated with long anterior strut grafts [29]. Long-term data of patients with one-level corpectomy, cages and additional cervical plate show perfect results with a high fusion rate [30].

However, newer stand-alone cages without an anterior plate may avoid some of the complications seen with conventional methods, especially dysphagia. Dysphagia can range from mild discomfort to inability of control of the muscles used for swallowing. Persistent dysphagia can result in serious medical complications, potential significant morbidity and possible mortality. Although the exact cause of postoperative dysphagia is unknown, it has been speculated that the profile of the plate, adhesions and scar tissue have an impact on the esophagus [29].
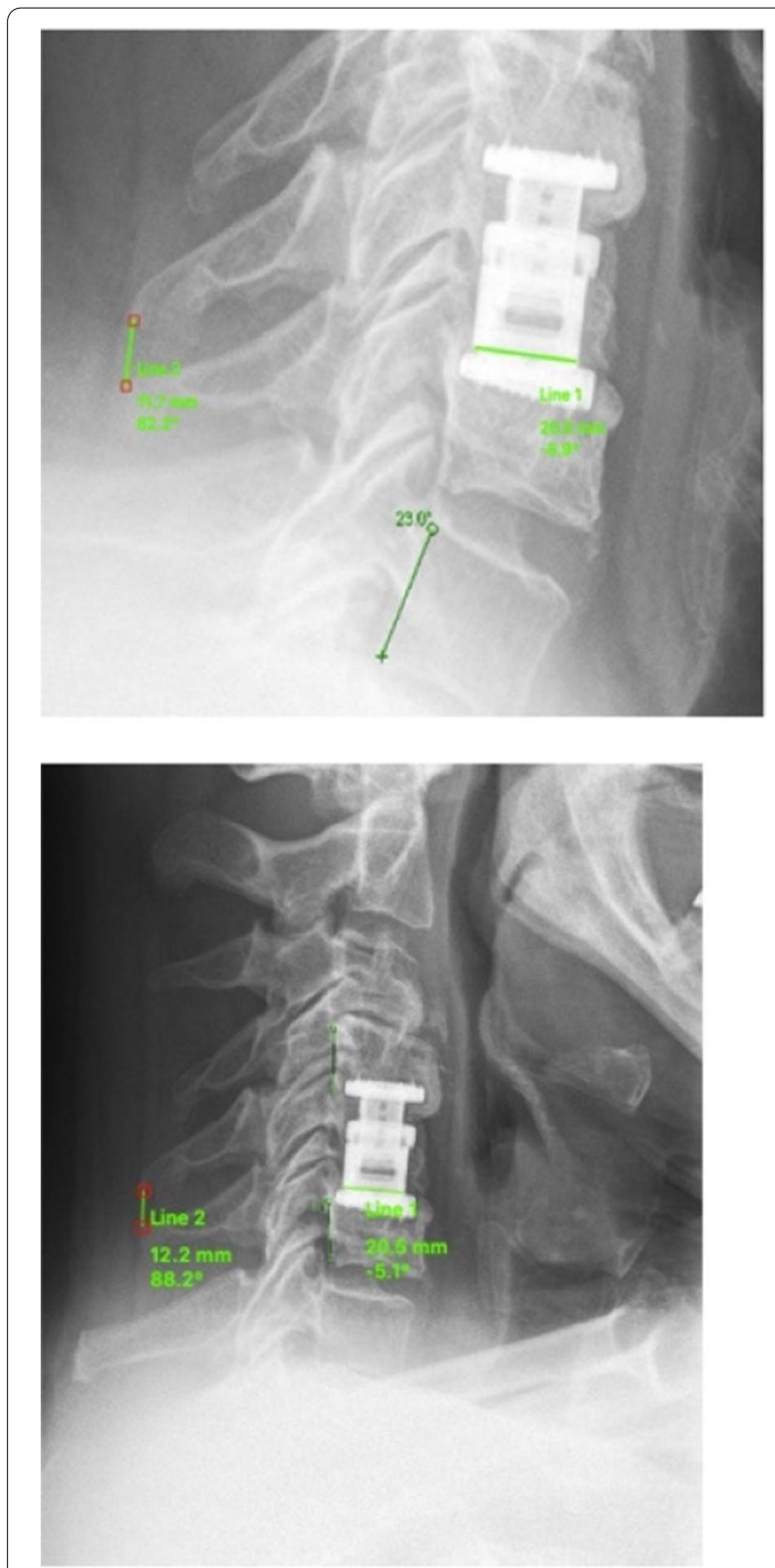

Fig. 5 Distance between the tips of the spinous processes on flexion is $12.2 \mathrm{~mm}$ and $11.7 \mathrm{~mm}$ in extension in lateral views

Lately in case of $\mathrm{ACDF}$, there is a widespread usage of stand-alone cages in mono- and bi-segmental without anterior plate, which has a lot of problems [31, 32].

Apart from the potential soft-tissue problems that come along with anterior plating of the cervical spine, it may seem obvious that an additional plate adds stability to a multilevel anterior construct from a biomechanical perspective. In biomechanical studies, additional 


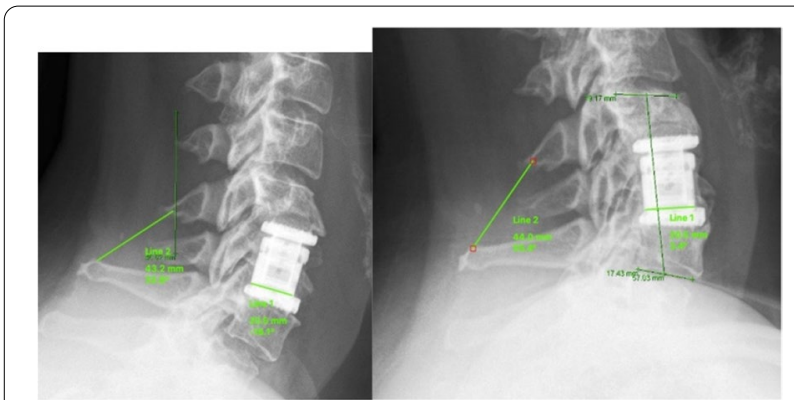

Fig. 6 Distance between the tips of the spinous processes on flexion is $44 \mathrm{~mm}$ and $43.2 \mathrm{~mm}$ in extension of lateral views

Table 2 Comparison between anterior DSH, posterior DSH and CD postoperatively and at the follow-up

\begin{tabular}{llll}
\hline & Pre-operative & Post-operative & P \\
\hline Anterior DSH & $25.7-63.9$ & $18.6-63.9$ & 0.237 N. S \\
Range & 37.0 & 34.9 & \\
Mean \pm S.D. & 11.12 & 11.20 & \\
Posterior DSH & $19.3-66.1$ & $15.1-56.9$ & 0.231 N. S \\
Range & 32.9 & 30.8 & \\
Mean \pm S.D. & 11.90 & 10.85 & \\
Dist. Posterior wall (CD) & $1.0-7.7$ & $0.5-5.7$ & $0.05^{*}$ \\
Range & 3.4 & 2.9 & \\
Mean \pm S.D. & 1.51 & 1.23 & \\
\hline
\end{tabular}

* Significant difference at $p<0.05$

N.S. Non-significant

anterior plating provides increased stiffness, especially in extension [33, 34]. On the other hand, it also reverses graft loads and excessively loads the graft or cage in extension, which may promote failure of multilevel constructs [34].

We observed only very little subsidence but no significant loss of lordotic correction. Cage subsidence does not necessarily mean a loss of segmental and GCL. If the collapse of the anterior part of the involved disc space is not higher than that of the posterior part, the local lordosis will be preserved despite the disc space collapse [35, 36]. As surgeons, we should adopt an appropriate technique to avoid over distraction of the disc space, oversizing of the cage and injury of the endplates, especially the anterior border of superior endplate where it is less mineralized [35, 36].

As for the clinical results of the study, subsidence was not found to have any impact on clinical satisfaction.

In a comparable study on cage-assisted interbody fusion with a two-years follow-up, subsidence and cage migration were present in most patients but without clinical sequelae [37]. Furthermore, the two-year radiographic follow-up demonstrated preservation of the physiological alignment of the cervical spine and presence of solid fusion [37].

The limitations of this study include its small sample size. The limited number of patients is not enough to evaluate the percentage of the postoperative dysphagia in such a population [38]. Further studies with long-term follow-up are required to assess the effect of such cages on the adjacent level. Meanwhile, until now, we do not have enough studies about the function and the biomechanics of the expandable stand-alone-cages, which can help us to replace VB with enough extension of the cage to lock the posterior facets and prevent any movement in the segment.

\section{Conclusion}

Application of a stand-alone expandable titanium cage in the cervical spine after one or two level ACCF without additional posterior fixation or anterior plating is a safe procedure that normally results in fusion. In this series, neither significant subsidence of the cages nor significant loss of lordotic correction were seen. However, it may need a surgical skill to limit the over-distraction of the cage to decrease the percentage of the subsidence or to prevent its loosening. In other words, if the cage is primarily stable with a fair and enough distraction forces and there is an intact posterior column, extra anterior plating is not a necessity.

\section{Abbreviations}

ACCF: Anterior cervical corpectomy and fusion; VAS: Visual Analog Scale; NDI: Neck Disability Index; GCL: Global cervical lordosis; FSL: Fusion site lordosis; Ant. DSH: Anterior interbody space height; Pot. DSH: Posterior interbody space

Table 3 Correlation between GCL, ant. DSH and posterior DSH on both VAS and NDI

\begin{tabular}{|c|c|c|c|c|c|c|}
\hline & \multicolumn{2}{|l|}{ VAS Neck } & \multicolumn{2}{|l|}{ VAS Arm } & \multicolumn{2}{|l|}{ ODI } \\
\hline & $\begin{array}{l}\text { Correlation } \\
\text { coefficient }\end{array}$ & $p$-value & $\begin{array}{l}\text { Correlation } \\
\text { coefficient }\end{array}$ & $p$-value & $\begin{array}{l}\text { Correlation } \\
\text { coefficient }\end{array}$ & $p$-value \\
\hline Glob. Lordosis & -0.222 & 0.217 & -0.241 & 0.203 & -0.208 & 0.227 \\
\hline Ant. DSH & -0.017 & 0.809 & -0.113 & 0.604 & -0.012 & 0.902 \\
\hline Post. DSH & -0.036 & 0.898 & -0.072 & 0.77 & -0.031 & 0.875 \\
\hline
\end{tabular}


height; CD: The distance of the cage to the posterior wall of the vertebral body; ACDF: Anterior cervical discectomy and fusion; SCS: Spinal canal stenosis; VB: Vertebral body; OPLL: Ossification of the posterior longitudinal ligament; CT: Computer tomography; MRI: Magnetic resonance imaging; RA: Rheumatoid arthritis; DM: Diabetes mellitus.

\section{Supplementary Information}

The online version contains supplementary material available at https://doi. org/10.1186/s12891-021-04883-5.

Additional file 1. Supplement: Preoperative and Postoperative neurological status.

\section{Acknowledgements}

I would like to thank Prof. Heyde for his continuous help and support throughout the years of his supervision. It has been a great honor and pleasure to work with him on his paper.

\section{Authors' contributions}

MT is the first author who wrote the main manuscript text, analyzed, and reviewed it, ORCID 0000-0001-7577-4105• GO: Equal contribution authorship as the first author. AA: Reviewed the manuscript and prepared the Tables. AE: Prepared the figures and reviewed the manuscript. $\mathrm{CH}$ : Corresponding author, reviewed the manuscript, the results, and the whole work. All authors read and approved the final manuscript.

\section{Funding}

Open Access funding enabled and organized by Projekt DEAL.

\section{Availability of data and materials}

You can connect the first author Dr. Mohamed Tohamy or the corresponding author Prof. Christoph Heyde. All data and material are available at any time.

\section{Declarations}

\section{Ethics approval and consent to participate}

According to bylaw number 15 , which regulates the rules of the ethics committee of the syndicate of physicians, Thueringen (Address: Im Semmicht 33, 07751 Jena-Maua), this study does not need the approval of the ethics committee. This is according to the decision of the legal section of the ethics committee of the syndicate of physicians, Thueringen (Dated: Wednesday 25.07.2018, 8:34).

The Name of the ethics committee: Ethikkommission der Landesärztekammer Thüringen.

All methods in the study were carried out in accordance with the Helsinki guidelines and declaration or any other relevant guidelines. We confirm that an informed consent was obtained from all our patients. We confirm that a written and verbal consent was obtained from all subjects. We have no patient under 18years old.

We confirm that there are no experimental trials in our study.

\section{Consent for publication}

Not Applicable.

\section{Competing interests}

We declare that the authors have no competing interests as defined by BMC or other interests that might be perceived to influence the results and/or discussion reported in this paper.

\section{Author details}

${ }^{1}$ Spine Unit, Martin-Ulbrich-Haus Rothenburg, Horkaer Str. 15-21, 02929 Rothenburg, Oberlausitz, Germany. ${ }^{2}$ Spine Departement, Helios Klinikum Erfurt, Nordhäuser Str. 74, 99089 Erfurt, Germany. ${ }^{3}$ Ligamenta Spine Center, Walter-Kolb-Street 9-11, 60594 Frankfurt am Main, Germany. ${ }^{4}$ Department of Orthopedics, Trauma and Plastic Surgery, University Hospital Leipzig, Liebigstrasse 20, 04179 Leipzig, Germany. ${ }^{5}$ Department of Orthopedic and Trauma Surgery, Assiut University Hospitals, Assiut, Egypt. ${ }^{6}$ Department of Orthopedics, Trauma and Plastic Surgery, University Hospital Leipzig, 04103 Leipzig, Germany.

Received: 15 May 2021 Accepted: 26 October 2021

Published online: 03 January 2022

\section{References}

1. Patil PG, Turner DA, Pietrobon R. National trends in surgical procedures for degenerative cervical spine disease: 1990-2000. Neurosurgery. 2005;57:753-8 discussion 753-8.

2. Wang L, Hu B-W, Wang L, Song Y-M, Yang X, Liu L, et al. Clinical and radiographic outcome of dynamic cervical implant (DCI) arthroplasty for degenerative cervical disc disease: a minimal five-year follow-up. BMC Musculoskelet Disord. 2018;19:101.

3. Lee SH, Son DW, Lee JS, Kim DH, Sung SK, Lee SW, et al. Differences in cervical sagittal alignment changes in patients undergoing Laminoplasty and anterior cervical discectomy and fusion. Neurospine. 2018;15:91-100.

4. Wang T, Wang H, Liu S, An H-D, Liu H, Ding W-Y. Anterior cervical discectomy and fusion versus anterior cervical corpectomy and fusion in multilevel cervical spondylotic myelopathy. Medicine (Baltimore). 2016;95:e5437.

5. Carette S, Fehlings MG. Clinical practice. Cervical radiculopathy. N Engl J Med. 2005;353:392-9.

6. Mitsunaga LK, Klineberg EO, Gupta MC. Laminoplasty techniques for the treatment of multilevel cervical stenosis. Adv Orthop. 2012;2012:1-15.

7. Standen GR. Wiskott-Aldrich syndrome: a multidisciplinary disease. J Clin Pathol. 1991;44:979-82.

8. Song K-J, Yoon S-J, Lee K-B. Three- and four-level anterior cervical discectomy and fusion with a PEEK cage and plate construct. Eur Spine J. 2012;21:2492-7.

9. Deutsch H, Haid RW, Rodts GE, Mummaneni PV. Postlaminectomy cervical deformity. Neurosurg Focus. 2003;15:1-5.

10. Son S, Lee SG, Yoo CJ, Park CW, Kim WK. Single stage circumferential cervical surgery (selective anterior cervical corpectomy with fusion and laminoplasty) for multilevel ossification of the posterior longitudinal ligament with spinal cord ischemia on MRI. J Korean Neurosurg Soc. 2010:48:335-41.

11. Robinson RA, Smith GW. Anterolateral cervical disc removal and interbody fusion for cervical disc syndrome. SAS J. 2010;4:34-5.

12. Eleraky MA, Llanos C, Sonntag VK. Cervical corpectomy: report of 185 cases and review of the literature. J Neurosurg. 1999;90:35-41.

13. Lin D, Ding Z, Lian K, Hong J, Zhai W. Cervical ossification of the posterior longitudinal ligament: anterior versus posterior approach. Indian J Orthop. 2012;46:92-8.

14. Edwards CC, Heller JG, Murakami H. Corpectomy versus Laminoplasty for multilevel cervical myelopathy. Spine (Phila Pa 1976). 2002;27:1168-75.

15. Emery SE, Fisher RJS, Bohlman HH. Three-level anterior cervical discectomy and fusion. Spine (Phila Pa 1976). 1997;22:2622-4.

16. ZdeblickTA, Hughes SS, Riew KD, Bohlman HH. Failed anterior cervical discectomy and arthrodesis. Analysis and treatment of thirty-five patients. J Bone Joint Surg Am. 1997;79:523-32.

17. Nottmeier EW, Gordon Deen H, Patel N, Birch B. Cervical kyphotic deformity correction using 360-degree reconstruction. J Spinal Disord Tech. 2009;22:385-91.

18. Mayr MT, Subach BR, Comey CH, Rodts GE, Haid RW. Cervical spinal stenosis: outcome after anterior corpectomy, allograft reconstruction, and instrumentation. J Neurosurg. 2002. https://doi.org/10.3171/spi.2002.96.1. 0010.

19. Delgado DA, Lambert BS, Boutris N, McCulloch PC, Robbins AB, Moreno $M R$, et al. Validation of digital visual analog scale pain scoring with a traditional paper-based visual analog scale in adults. J Am Acad Orthop Surg Glob Res Rev. 2018;2:e088.

20. Cramer H, Lauche R, Langhorst J, Dobos GJ, Michalsen A. Validation of the German version of the neck disability index (NDI). BMC Musculoskelet Disord. 2014;15:91.

21. Faldini C, Miscione MT, Acri F, Leonetti D, Nanni M, Chehrassan M, et al. Single level cervical fusion by an anterior approach using autologous bone graft influences the adjacent levels degenerative changes: clinical 
and radiographic results at 10-year minimum follow-up. Eur Spine J. 2012. https://doi.org/10.1007/s00586-012-2215-1.

22. Gercek E, Arlet V, Delisle J, Marchesi D. Subsidence of stand-alone cervical cages in anterior interbody fusion: warning. Eur Spine J. 2003;12:513-6.

23. Choudhri TF, Mummaneni PV, Dhall SS, et al. Guideline update for the performance of fusion procedures for degenerative disease of the lumbar spine. Part 4: radiographic assessment of fusion status. J Neurosurg Spine. 2014;21:23-30.

24. Lee C-S, Chung SS, Choi SW, Yu JW, Sohn MS. Critical length of fusion requiring additional fixation to prevent nonunion of the lumbosacral junction. Spine (Phila Pa 1976). 2010;35:E206-11.

25. Cannada LK, Scherping SC, Yoo JU, Jones PK, Emery SE. Pseudoarthrosis of the cervical spine: a comparison of radiographic diagnostic measures. Spine (Phila Pa 1976). 2003;28:46-51.

26. Ghiselli G, Wharton N, Hipp JA, Wong DA, Jatana S. Prospective analysis of imaging prediction of pseudarthrosis after anterior cervical discectomy and fusion: computed tomography versus flexion-extension motion analysis with intraoperative correlation. Spine (Phila Pa 1976). 2011;36:463-8.

27. Mostafa D, Aboushelib M. Bioactive-hybrid-zirconia implant surface for enhancing osseointegration: an in vivo study. Int J Implant Dent. 2018;4:20.

28. Luo J, Cao K, Huang S, Li L, Yu T, Cao C, et al. Comparison of anterior approach versus posterior approach for the treatment of multilevel cervical spondylotic myelopathy. Eur Spine J. 2015;24:1621-30.

29. Li Z, Guo Z, Hou S, Zhao Y, Zhong H, Yu S, et al. Segmental anterior cervical corpectomy and fusion with preservation of middle vertebrae in the surgical management of 4-level cervical spondylotic myelopathy. Eur Spine J. 2014;23:1472-9.

30. Daubs MD. Early failures following cervical corpectomy reconstruction with titanium mesh cages and anterior plating. Spine (Phila Pa 1976). 2005;30:1402-6.

31. Dufour T, Huppert J, Louis C, Beaurain J, Stecken J, Aubourg L, et al. Radiological analysis of 37 segments in cervical spine implanted with a peek stand-alone device, with at least one year follow-up. Br J Neurosurg. 2010. https://doi.org/10.3109/02688691003793029.

32. Kolstad F, Nygaard ØP, Andresen H, Leivseth G. Anterior cervical arthrodesis using a "stand alone" cylindrical titanium cage: prospective analysis of radiographic parameters. Spine (Phila Pa 1976). 2010. https://doi.org/10. 1097/BRS.0b013e3181d259c1.

33. Kandziora F, Pflugmacher R, Schaefer J, Scholz M, Ludwig K, Schleicher P, et al. Biomechanical comparison of expandable cages for vertebral body replacement in the cervical spine. J Neurosurg. 2003;99:91-7.

34. DiAngelo DJ, Foley KT, Vossel KA, Rampersaud YR, Jansen TH. Anterior cervical plating reverses load transfer through multilevel strut-grafts. Spine (Phila Pa 1976). 2000;25:783-95.

35. Wu W-J, Jiang L-S, Liang Y, Dai L-Y. Cage subsidence does not, but cervical lordosis improvement does affect the long-term results of anterior cervical fusion with stand-alone cage for degenerative cervical disc disease: a retrospective study. Eur Spine J. 2012;21:1374-82.

36. Bartels RHMA, Donk RD, Feuth T. Subsidence of stand-alone cervical carbon fiber cages. Neurosurgery. 2006;58:502-8 discussion 502-8.

37. Schmieder K, Wolzik-Grossmann M, Pechlivanis I, Engelhardt M, Scholz $M$, Harders A. Subsidence of the wing titanium cage after anterior cervical interbody fusion: 2-year follow-up study. J Neurosurg Spine. 2006:4:447-53.

38. Faber J, Fonseca LM. How sample size influences research outcomes. Dental Press J Orthod. 2014;19:27-9.

\section{Publisher's Note}

Springer Nature remains neutral with regard to jurisdictional claims in published maps and institutional affiliations. 